\title{
VISÃO DE MUNDO E AGROECOLOGIA: O CASO DOS AGRICULTORES DE MEDIANEIRA - PARANÁ
}

Evandro de Oliveira ${ }^{1}$

Adilson Francelino Alves ${ }^{2}$

\begin{abstract}
Resumo: Observando a paisagem da agricultura do Oeste do Paraná tomado pela agricultura convencional é difícil acreditar que algum agricultor opte pela agroecologia. Todas as evidências econômicas, técnicas e produtivas estão contra essa decisão. No entanto um pequeno grupo de agricultores se mantém fiéis a esse tipo de agricultura. Este artigo parte então da seguinte pergunta por que praticar a agroecologia? E por que, depois de aderir a ela alguns desistem? Para dar conta dessa pergunta optamos por explicitar a voz dos próprios atores, adotando uma metodologia que evidenciasse a interação entre visão de mundo e agroecologia, ou seja, quais fatores culturais, sociais, econômicos influenciam produtores rurais a adotarem e manterem a agroecologia, bem como também não adotarem e não manterem a mesma. Para isso utilizamos como metodologia de pesquisa o Método Documentário, proposto por Karl Mannheim no início do século XX, que se propõe a analisar como se forma a visão de mundo e como ela orienta as ações dos sujeitos. Quando foi proposta essa metodologia rompia com a visão positivista que imperava nas ciências sociais da época e ainda hoje tem capacidades explicativas muito úteis que procuraremos demonstrar no artigo.
\end{abstract}

Palavras-chave: Método documentário, produção agroecológica, agricultura familiar, visões de mundo

\section{WORLDVIEWS AND AGROECOLOGY: THE CASE OF FARMERS OF MEDIANEIRA - PARANÁ}

\begin{abstract}
Observing the landscape of Western Paraná agriculture taken by conventional agriculture, it is difficult to believe that any farmer opts for agroecology. All the economic, technical and productive evidence is against this decision. However, a small group of farmers remains faithful to this type of agriculture. This article then starts from the following question: Why practice agroecology? And why, after joining it some give up? In order to answer this question, we chose to make explicit the voice of the actors themselves, adopting a methodology that evidences the interaction between world vision and agroecology, that is, what cultural, social and economic factors influence rural producers to adopt and maintain agroecology, as well as also not adopting and not maintaining it. For this we use as research methodology the Documentary Method, proposed by Karl Mannheim in the early twentieth century, which proposes to analyze how the world view is formed and how it guides the actions of the subjects. When it was proposed, this methodology broke with the positivist view that prevailed in the social sciences of the time and still has very useful explanatory capacities that we will try to demonstrate in the article.
\end{abstract}

Key words: Documentary method, agroecological production, family agriculture, worldviews

\section{Introdução}

Este artigo tem o propósito de analisar a influência de aspectos culturais e sociais na adoção e manutenção da agricultura agroecológica identificando fatores que influenciam agricultores familiares a adotarem ou não práticas agroecológicas bem como manterem-se ou não na mesma.

A pesquisa foi realizada no município de Medianeira, localizado no Oeste do Paraná, em específico numa associação de agricultores denominada Associação dos agricultores familiares e Ecológicos de Medianeira (AAFEMED). Esta associação é composta por cerca de cem associados, em sua grande maioria produtores convencionais, mas também de produtores agroecológicos. Foram realizadas oito entrevistas qualitativas gravadas com gravador de voz e

\footnotetext{
${ }^{1}$ Doutorando no programa de pós-graduação interdisciplinar em ciências humanas na Universidade Federal de Santa Catarina.

${ }^{2}$ Doutor em Ciências Humanas - UFSC. Professor associado da Universidade Estadual do Oeste do Paraná
} 
transcritas baseando-se no Método Documentário. Este método foi proposto por Mannheim em 1922 através do texto Beiträge zur Theorie der Weltanschaungs interpretation, traduzido trinta anos depois para o inglês sob o título Essays on the sociology of Knowledge. Mannheim se propõe a analisar as visões de mundo (Weltanschauungen) o que abre enormes possibilidades metodológicas dentro da sociologia do conhecimento. Parcialmente esquecido por anos, na década de 1990 o sociólogo alemão Ralf Bohnsack retoma este texto e o atualiza propondo a retomada do Método Documentário de interpretação dando-lhe instrumentos operacionais transformando-o em uma ferramenta de análise para a pesquisa social empírica (WELLER, et alli. 2002). O método coloca no centro da análise empírica o sentido dado pelos agentes/atores às suas ações o que implica a reconstrução do processo de uma ação (ou ações) inseridas em um contexto social particular.

Para Mannheim a visão de mundo de um ator é resultado de um conjunto de experiências e vivências vinculadas a uma estrutura que se constitui em uma base comum, em que vários níveis experienciais são perpassados por múltiplos indivíduos. Contudo, é necessário advertir que não se deve confundir visão de mundo com imagens de mundo:

[...] não podemos confundir visões de mundo com imagens de mundo ou com algo que tenha sido pensado ou produzido teoricamente: as visões de mundo são construídas a partir das ações práticas e pertencem ao campo que Mannheim definiu como sendo o do conhecimento ateórico. Assim sendo, a compreensão das visões de mundo e das orientações coletivas de um grupo só é possível a partir da explicação e da conceitualização teórica desse conhecimento ateórico (WELLER, 2003, p. 3).

Nessa metodologia o desafio está em captar as visões de mundo de acordo com conceitualizações teóricas e documentais do conhecimento compartilhado e vivido pelos indivíduos no cotidiano. Dessa forma, elas não se constituem apenas no conjunto das formações espirituais de uma época, nem na coletividade de uma época, mas em espectro mais amplo da vida social dos indivíduos. Para Mannheim, as visões de mundo estão localizadas:

[...] na totalidade de uma série de vivências/experiências interconectadas estruturalmente que podem derivar, tanto da formação de grupos sociais como das criações espirituais. As visões de mundo não se apresentam como um volume perceptível, mas podem ser compreendidas quando analisadas transversalmente e em relação a um problema específico, constituindo-se dessa forma como objeto teórico (WELLER et. Ali., 2002 p. 378).

Dessa forma o autor abre a análise para a transversalidade e a especificidade presentes nos discursos dos atores, no caso da pesquisa as noções sobre agroecologia, constituem um objeto teórico fundamental, que pode fornecer informações válidas para se compreender como os atores interpretam e agem coletivamente, quando compartilham, no cotidiano, uma proposta de 
agricultura alternativa como é o caso da agroecologia. Mannheim, ao questionar se a visão de mundo de uma época pode ser ou não compreensível cientificamente o faz interrogando sobre a possibilidade de determina-la de maneira objetiva e científica, para dar conta desse desafio propõe como processo metodológico de interpretação da que ele denomina de Método Documentário, em que os objetos de estudo são analisados como um documento. Para isso, ele propõe que todo produto cultural pode ser analisado, levando-se em conta três níveis de sentido (Sinnschichten). O primeiro compreende "a coisa em si" desconectada de uma função mediadora. Após, temos dois sentidos ou elementos mediadores, o sentido expressivo, e, finalmente, o documentário:

a) Um nível objetivo ou imanente, dado naturalmente (por exemplo, num gesto, num símbolo ou ainda na forma de uma obra de arte);

b) um nível expressivo, que é transmitido através das palavras ou das ações (por exemplo, como expressão de ou como reação $a$ algo);

c) e um nível documentário, ou seja, como documento de uma ação prática. (WELLER, et. alli, p. 386)

Desse modo, para capturar a realidade, no sentido documentário proposto pela metodologia Mannheim, é necessário avançar na compreensão e, mais que isso, na apreensão dos produtos culturais de um modo tridimensional e panóptico. No caso do estudo em tela, por exemplo, implica compreender não apenas os elementos constituídos por práticas sociais determinadas e imanentes que, se apreendidas apenas desta forma, revelam tão somente a aparência de relação mais profunda com a realidade local e com os discursos teóricos construídos globalmente.

A busca da síntese, como postulado e objetivo de seu projeto metodológico, implica compreender a cultura como um processo histórico. Assim, um sistema de conceitos deve ser operacionalizado para "cruzar várias esferas da atividade cultural e também cruzar sucessivos estágios culturais" (MANNHEIM, 1952, p. 75). Para que o procedimento metodológico se efetive, é necessário o seu desdobramento em duas etapas: I) transformar em documento aquilo que é ateórico; II) observar incessantemente que o sistema de conceitos utilizado não se processa separadamente da realidade objetiva dos sujeitos, caminhando num movimento dialético de integração entre a teoria e a empiria.

Entretanto, Mannheim observa que esse processo de racionalização não se procede como uma dedução lógica de princípios teóricos. Além disso, há a necessidade de observar que essa conexão com outros documentos, fenômenos históricos e culturais não implica a determinação e nem o privilégio de um sobre o outro. 
Mannheim não se utiliza do termo irracional, mas ateórico, sinalizando que as experiências em análise são ainda não conceituadas e teorizadas. Além disso, para ele, toda experiência possui sua própria história. As experiências sociais ou individuais não são meros eventos na vida, mas estão profundamente enraizadas na história da sociedade da qual fazem parte. Assim, a opção ou não pela agroecologia possui múltiplas dimensões, pois conecta-se a diversas escalas que os atores interpretam e ressignificam dentro do conjunto dos seus valores culturais. Mannheim considera mais importante o como uma experiência social é constituída do que o por quê ou o que ela é. Ele se volta para a fina e fluida camada entre a experiência, intuição e teoria; para aquilo que, à primeira vista se aparenta como obscuro, caótico, simples, banal, ateórico, desprovido de qualquer sentido e significação histórica. Faz assim um apelo ao uso da razão, pela confiabilidade em que a razão possa ser o instrumento analítico capaz de fazer emergir as experiências submetidas ao campo ateórico, todavia com uma diferença: não mais como caóticas, mas cunhadas por conceitos, legítimos na ordem do mundo, portanto comunicadas, interpretadas e partilhadas em comum.

Ao trazer como proposta metodológica a documentação das experiências ateóricas, instiga-nos a pensar sobre o mundo atual em sua profusão de ações, discursos e sobre a velocidade com que as informações invadem os espaços tradicionais. E faz-nos perguntar, se a instantaneidade do tempo poderia aniquilar os espaços singulares e em seu lugar impor a homogeneização das culturas e dos saber-fazer local ou se pelo contrário a resistência cultural/produtiva/reprodutiva da vida em escala local pode se contrapor ao reinterpretar e ressignificar os padrões.

Do total das entrevistas qualitativas foram utilizadas quatro: três de agricultores agroecológicos, aos quais foram atribuídos os seguintes códigos $\mathbf{B m}^{3}, \mathbf{A m}$ e $\mathbf{J f}$ e um agricultor convencional denominado $\mathbf{E m}^{4}$. As demais entrevistas foram utilizadas como elementos complementares para esta pesquisa.

Relativo a base teórica-metodológica, utilizamos autores que discutem o conceito de agroecologia, cultura e agricultura familiar. Neste texto são utilizadas as contribuições dos seguintes autores que discutem o conceito de cultura: (Certeau (2008), Eagleton (2005), Laraia (2009), Geertz (2008) e Bauman (2012); autores que trabalham o conceito de agroecologia (Altieri (2004), Caporal (2011) Gliessman (2000), Leff (2002), Brandenburg (2002), e Wezel et al (2009) ), e por último autores que discutem o conceito de agricultura familiar (Abramovay (1990) Abramovay et al (2005) e Bauanin (2006) Bauanin et al(2003).

\footnotetext{
${ }^{3}$ Estes códigos são utilizados para preservar a identidade dos produtores. As letras em maiúsculo representam o nome fictício dado a estes produtores, e as letras minúsculas simbolizam o sexo, sendo m para masculino e f para feminino.

${ }^{4}$ Este produtor atualmente é agricultor convencional, mas praticou por muitos anos agroecologia.
} 
Com o objetivo de compreender os processos e a redes observadas na pesquisa foram também utilizados alguns conceitos de Norman Long na Perspectiva Ator-Orientado basicamente os conceitos de campos de batalha do conhecimento, interface social, cultura e significados e agencia, permitindo assim uma compreensão dos conflitos, negociações e mudanças sociais advindos de projetos de desenvolvimento rural, esta teoria foi utilizada no sentido de compreender os processos macroestruturais da agricultura servindo como suporte teórico para compreender as visões de mundo dos atores; também utilizamos alguns da Teoria Ator-Rede de Michel Callon e Bruno Latour que nos permitiu compreender alguns elementos das redes as redes nos quais os produtores estão inseridos e nos ofereceu os conceitos de híbridos e tradução. A noção de hibridização permite observar como podem ocorrer processos de interação entre tecnologias produtivas divergentes na medida em que são adotadas pelos atores; o conceito de tradução por sua vez conecta-se à forma como a agricultura convencional e agroecológica é compreendida pelos diferentes agentes e como se conectam a cadeias de conceitos e significados culturais.

Nesse sentido a pesquisa procurou captar a visão de mundo dos atores observando na sua estrutura social o sentido que eles mesmos dão às suas ações, sejam no plano racional econômico, valores herdados, saber fazer, opções tecnológicas etc. Dessa forma, não partiremos de uma definição de cultura dada a priori, mas a interpretação que os próprios autores fazem de si e do meio em que vivem e de como leem a realidade e constroem suas visões de mundo.

\section{Os Benefícios Advindos da Agroecologia}

Num primeiro momento da pesquisa, notamos que a agroecologia pode propugnar diversos benefícios aos seus praticantes. E estes benefícios fazem com que os produtores adotem a agroecologia, bem como também mantenham a pratica. Um exemplo é evidenciado no agricultor Bm, que é questionado sobre quais os benefícios de praticar agroecologia. Ele responde que a procura pelo produto agroecológico é boa, que ele vende bem seus produtos, que a propaganda em torno de produtos desta faceta ajuda a melhorar as vendas. Bm também destaca que a agroecologia faz bem ao próprio produtor, "tu se sente melhor né, mais disposição para trabalha" (Bm: Entrevista 1 Agricultor, pesquisa de Campo Linha 171).

Caporal e Costabeber (2004) subentendem que a concretização dos princípios agroecológicos resulta em práticas agrícolas ecológicas, que tem por efeito produtos de qualidade biológica superior ao produto advindo da agricultura convencional, fato verificado na fala de Bm. O agricultor Em também destaca a qualidade dos produtos advindos da agroecologia. Para o produtor era gratificante levar um produto saudável e de qualidade para a venda, ressalta também que os consumidores gostavam do produto e sentiam a diferença entre o 
produto agroecológico e convencional. Ainda nesta ideia, o produtor Am enfatiza que a agroecologia consegue produzir qualidade e quantidade, basta apenas tempo para o agricultor se dedicar a atividade.

Outro aspecto proporcionado pela agroecologia é a ética relativa à produção. O produtor Bm enfatiza que é importante vender produtos com qualidade para os consumidores, pois, segundo o mesmo, "saúde não é só pra mim, é para os outros também”. A consciência de produzir também com qualidade "para os outros" demonstra ética nas atitudes do agricultor. Corroborando com a ideia de $\mathbf{B m}$, Am também tem preocupação em vender produtos saudáveis para o consumidor, em suas palavras: " se eu quero o bem pra mim, eu quero pra minha família e quero para os outros também, o consumidor" (Am: Entrevista 1 Agricultor, pesquisa de Campo Linhas 417-418).

Nota-se que os produtores Am e Bm tem o compromisso de produzir de maneira ética, isto é, produzir levando em conta a saúde do consumidor. Conforme Caporal (2011), a agroecologia requer mudanças não apenas de maneira produtiva, mas mutações envolvendo questões culturais e sociais que propiciem novas percepções dos atores envolvidos com a prática. Entendemos que a ética dos agricultores Bm e Am são mudanças benéficas proporcionadas pela agroecologia.

Entretanto, apesar dos vários benefícios proporcionados pela agroecologia, os agricultores pesquisados também destacaram diversas dificuldades que os mesmos enfrentam. A seguir discutiremos este assunto.

\section{Dificuldades em Praticar Agroecologia}

Foi evidenciado na pesquisa que alguns produtores encontram dificuldades logo na adesão da agroecologia. Muitos agricultores que adotam a agroecologia antes de disso praticavam agricultura convencional. Com isso, estes produtores tiveram de adaptar suas propriedades ao novo modelo produtivo. Esta adaptação, que é chamada de transição agroecológica, torna-se, muitas vezes, um obstáculo para o produtor. Em ressalta que os dois primeiros anos em que estava aderindo a agroecologia, o mesmo não podia vender o produto como agroecológico, mas tinha que plantar desta forma. Entendemos que este procedimento foi necessário devido aos antigos hábitos adotados por este produtor, estes procedimentos que englobavam utilização de fertilizantes químicos e agrotóxicos, influenciaram na transição para a prática da agroecologia. De acordo com Caporal (2011), a transição agroecológica instala mudanças nos agroecossistemas que abrangem desde os cultivos plantados até modificações sociais e culturais nos produtores. Estas mutações acontecem paulatinamente, principalmente no requisito de mudar os hábitos produtivos. Por sua vez, Bauman (2012) discute que cultura é, 
simultaneamente, conservadora e inovadora, conserva hábitos culturais e ao mesmo tempo cria novos padrões culturais. Neste sentido, o agricultor Em adquiriu novos hábitos culturais, que envolvem a agroecologia, o que nos remete a Laraia (2009) que destaca cultura como algo dinâmico, no qual os indivíduos podem adquirir novas habilidades e conhecimentos, como aconteceu com Em.

Long (2002) por sua vez enfatiza as mudanças socioculturais advindas de projetos de desenvolvimento rural, neste caso, o projeto em especifico é a agroecologia. A partir do momento em que Em aderiu a agroecologia novos conhecimentos foram adquiridos pelo mesmo, ou seja, neste campo de batalha do conhecimento houve interações e "negociações" entre o produtor e o técnico agroecológico, que teve por consequência mudanças nos saberes deste produtor. Estas mudanças nos remetem ao conceito de agência. $\mathrm{O}$ conceito de agência enfatiza a capacidade que um indivíduo tem em aprender com as experiências de outras pessoas, ou seja, com o conhecimento ateórico de outros atores. Entendemos que na transição agroecológica Em teve que aprender muitas técnicas para serem aplicadas em sua propriedade. Avaliamos que a transição agroecológica pode muitas vezes fazer com que os produtores não adotem a agroecologia, pois além destes produtores terem de realizar mudanças radicais em suas propriedades e modos de vida, é uma transição de no mínimo dois anos, onde os agricultores devem plantar de forma agroecológica mas não podem vender o seu produto como tal.

Outra dificuldade que os agricultores agroecológicos enfrentam, são as difíceis condições de trabalho presentes no meio rural e na agroecologia. $\mathrm{O}$ agricultor $\mathbf{B m}$ destaca que sua plantação de cana fica longe de sua agroindústria. Bm não possui trator ou qualquer maquinário para transportar a lenha e a cana, ainda usa carroça de boi, e explica que com esse meio de transporte a dificuldade enfrentada por ele é imensa. Nota-se um antigo costume do meio rural ainda sendo praticado na propriedade, o uso de tecnologia de tração animal, porém, esta atividade ainda é realizada por necessidade e, segundo o produtor, lhe acarreta muitas dificuldades.

Já o agricultor Am enfatiza as diferentes condições de trabalho que permeiam o ambiente rural e urbano:

[...] que nem a cidade quem ta bem empregado às vezes tá melhor que nós, chego um final do mês ta ganhando, final do ano tem o décimo terceiro, a gente não tem essas coisa, de férias, a gente não existe férias pra nós [...] (Am: Entrevista 1 Agricultor, pesquisa de Campo Linhas 207-208).

Am retrata uma dificuldade não apenas dele, mas da maioria dos agricultores familiares. Segundo Abramovay (1990), os agricultores familiares são reféns da agricultura, pois os mesmos lidam com elementos vivos, eles estão submetidos a forças naturais. Um agricultor simplesmente 
não pode abandonar a propriedade por trinta dias, pois tem animais para cuidar e cultivos para colher. No quesito que envolve a falta de maquinário está diretamente ligado a descapitalização destes produtores, o acesso restrito a financiamentos, por isso têm dificuldades em conseguir tecnologias para a propriedade, como é o caso de $\mathbf{B m}$. Nas pequenas propriedades, geralmente, a mão-de-obra é familiar, o próprio agricultor administra o negócio, e por isso não há direitos sociais como décimo terceiro salário, férias remuneradas, fundo de garantia como naqueles que trabalham na iniciativa privada ou pública.

Outras dificuldades retratadas pelos agricultores, como trabalhar no sol quente e trabalhos braçais como enfatiza Bm, são as condições de trabalho do meio rural, que podem ser superadas parcialmente com recursos tecnológicos (como comprar um trator) ou financeiros (contratar empregado para o agricultor tirar férias), mas não serão superadas inteiramente devido às condições naturais que os agricultores estão submetidos. Diante deste argumento, entendemos que os agricultores de nossa pesquisa estão inseridos em redes limitadas, e com isso seu acesso a recursos humanos, financeiros e tecnológicos são reduzidos, causa da maioria dos problemas vivenciados pelos mesmos.

As condições de trabalho no meio rural são um dos motivos que ocasionam a falta de mão-de-obra. Por sua vez, a falta de mão-de-obra é outro obstáculo para estes produtores, segundo a produtora Jff, um dos motivos de na atualidade ter menos pessoas trabalhando no âmbito rural é a diminuição dos números de filhos que o casal tem. Ou seja, Jf se refere à mãode-obra familiar, que na atualidade as famílias são menores, tendo, por consequência, menos pessoas para trabalhar.

O agricultor Am também ressalta o mesmo problema, ele explica que seus pais ajudam no que podem, contudo ambos têm idade avançada, e muitas atividades já são incompatíveis com suas forças físicas. Suas filhas ainda são jovens, e vão à escola. Apenas Am e a esposa trabalham diariamente na propriedade, e segundo Am é difícil encontrar alguém para trabalhar no meio rural.

Bm também sofre com o mesmo problema, o produtor destaca que sua esposa e filha residentes na propriedade ajudam no que podem, mas além de ajudar na propriedade, têm os afazeres domésticos, o que limita ainda mais a contribuição delas na manutenção da propriedade.

Em salienta a dificuldade em achar pessoas para trabalhar quando se planta de maneira agroecológica, pois o serviço a ser realizado é sem ajuda de tecnologias modernas e geralmente "debaixo do sol quente".

Segundo Abramovay (1990), a mão de obra familiar é um fator preponderante para a agricultura familiar, os laços familiares permitem a reprodução desta categoria social. Este aspecto é evidente em Jff, Am e $\mathbf{B m}$; estes agricultores argumentam que algumas dificuldades 
enfrentadas pelos mesmos são o resultado do reduzido número de membros familiares na propriedade.

A teoria Ator Rede nos ensina que é através das conexões e redes formatadas pelos atores que os recursos, conhecimentos e outros atores são conectados e acessados pelos indivíduos. Supomos que uma das dificuldades dos agricultores em contratar mão-de-obra externa para trabalhar na propriedade seja por falta de recursos. Outro aspecto é a falta de material humano para trabalhar no meio rural. Na agricultura convencional esta lacuna é preenchida por máquinas, algo que não acontece na agricultura agroecológica, que ainda é carente de tecnologia e dependente de recursos humanos. Com isso, entende-se que as redes e conexões da agricultura convencional são mais "poderosas" que as redes da agroecologia, porque lhes propicia maior acesso a diferentes recursos.

No quesito de transporte e embalagem dos produtos, os agricultores pesquisados também encontram dificuldades. Jf sustenta que os pequenos agricultores têm dificuldade para embalar os produtos, o que se pode entender de sua fala é que os produtos agroecológicos muitas vezes não são bem vistos devido ao tipo de embalagem usado, "o bonito é o enlatado". Na concepção de Jff, seria difícil abrir uma indústria para embalagem dos seus produtos, pois a burocracia para montar a empresa seria grande demais. Enviar a uma indústria para ser embalado também está fora de questão, pois não teriam condições financeiras para isso.

Outro problema listado por Jf é o transporte da produção, uma vez que a associação está localizada em local distante da propriedade. Com isso a despesa com o transporte dos produtos aumenta e diminui a renda familiar.

Am também comenta sobre o transporte da produção, e ressalta que por residir na zona rural, tem despesas com o transporte e, em muitos casos, o lucro do produto vendido na associação não é suficiente para cobrir os gastos com o transporte.

Através da Teoria Ator Rede podemos ter a percepção das redes nas quais estes produtores estão inseridos. Suas conexões se limitam a: AAFEMED, BIOLABORE, CAPA, PAA, PNAE, COAFASO, Sindicato dos trabalhadores Rurais, Rede Ecovida, CRESSOL. Estas ligações ainda não possibilitaram a estes produtores meios de transportes ou recursos para embalar seus produtos, como no caso de $\mathbf{J f}$.

Muitos agricultores agroecológicos quando iniciam a produção de caráter agroecológico não têm todos os insumos necessários para esta prática. No caso de Jff, uma das dificuldades retratada pela mesma, é a compra de sementes. Segundo ela: "a gente compra semente né, nós não temos a produção própria da semente, que é um problema pra nós né” (Jf: entrevista 1 Agricultora, pesquisa de campo, linhas 168-169). Jf explica que não fazem o cultivo de sementes na propriedade por ser muito trabalhoso. 
Concluímos que a compra de sementes para serem usadas na propriedade acarreta mais despesas.

De fato, todas estas dificuldades destacadas neste tópico fazem com que muitos agricultores agroecológicos não adotem ou não mantenham a prática agroecológica. A desistência de agricultores de praticar agroecologia é nítida na fala do agricultor Bm. Ao ser questionado sobre o futuro da agroecologia, o mesmo responde:

Aqui em Medianeira parece que está indo para trás é quando nós começamos os curso por aí tinha um mundo de gente tinha sempre trinta, quarenta, cinquenta pessoas participando pra formatura de começa a faze um pouco de agroecologia e foi diminuindo e agora não sei... não sei como é que ta, não perguntei mais quantos tem que trabalha com isso[...](Bm: Entrevista 1 Agricultor, pesquisa de Campo Linhas 181-185).

De acordo com Brandenburg (2002) a agroecologia adquiriu forças suficientes para "lutar" contra a agricultura convencional. Não evidenciamos esta concepção em nossa pesquisa. Em nosso estudo o cenário encontrado é ao contrário àquele descrito por da Brandenburg (2002), ou seja, o número de agricultores agroecológicos diminuiu, algo que se constata na fala de $\mathbf{B m}$. $\mathrm{Na}$ atualidade apenas dez agricultores, contando com Bm, praticam agroecologia no município de Medianeira. Não temos os dados exatos de quantos agricultores iniciaram a prática agroecológica, mas com base no discurso de $\mathbf{B m}$, entendemos que muitos produtores desistiram de praticar agroecologia. Outro fator que influencia de forma significativa a pratica agroecológica é a assistência técnica, abordaremos esse assunto a seguir.

\section{Assistência Técnica}

A prática da agroecologia exige muitos conhecimentos por parte do agricultor. Geralmente, os produtores não dispõem de todos os saberes necessários para se praticar agroecologia, por isso a assistência técnica é fundamental na implantação desse sistema. A produtora Jf explica que quando adotou a agroecologia, tinha dificuldades nos cultivos, e que a assistência técnica foi fundamental nesse período e ainda é segundo a produtora para a mesma permanecer na agroecologia.

Mas não é apenas no aspecto produtivo que a assistência técnica é importante para o produtor; o agricultor Bm por exemplo enfatiza que tem uma quantidade de mata plantada em sua propriedade, pelo seu modo de falar, entende-se que é mata nativa da região. Bm retira um pouco de madeira deste local para usar em sua agroindústria, entretanto, ele esclarece que o técnico explicou o tanto de madeira que pode ser retirada, baseando-se na lei ambiental. Então, a ajuda do técnico não se restringe apenas nas plantações, mais também em orientar o produtor quanto ao uso consciente da madeira, respeitando a legislação ambiental. 
A assistência técnica é de vital importância para os agricultores e, consequentemente, para a agroecologia. Reportamo-nos a Gliessman para embasar nossa posição. Primeiro Gliessman afirma que, num agroecossistema devem-se levar em consideração os fatores ambientais que influenciam no crescimento da planta, a destacar: luz, temperatura, precipitação, vento, solo, umidade do solo, fogo e outros organismos. Em suma Gliessman compreende o agroecossistema como um complexo ambiental. No entanto, para o produtor obter esta visão exposta por Gliessman o mesmo deve ter muitos conhecimentos; e uma vez que a agroecologia se nutre de saberes de diversas ciências e saberes populares, isso aumenta ainda mais o arcabouço de conhecimentos que os agricultores teriam de possuir. Todavia, os agricultores não possuem todos esses saberes, sendo assim primordial a ajuda técnica para "completar" os saberes destes sobre a agroecologia. Em segundo, Gliessman também salienta que uma agricultura sustentável só será possível se ocorrer uma hibridização entre estratégias agrícolas locais e métodos ecológicos modernos. Para que isso se concretize é necessário que os saberes locais dos produtores sejam hibridizados com conhecimentos científicos, que são transmitidos pelos técnicos agrícolas através das visitas realizadas na propriedade ou em cursos de aperfeiçoamento realizados pelos órgãos responsáveis.

Em nosso estudo, identificamos que uma ONG denominada Centro de Apoio ao Pequeno Agricultor (CAPA), promove a agroecologia em várias regiões do Brasil. Um de seus núcleos está localizado no Município de Marechal Candido Rondon. O suporte oferecido por esta ONG aos agricultores agroecológicos é de suma importância para que os mesmos continuem a praticar a agroecologia. Jf destaca um curso de homeopatia promovido pela instituição, do qual ela participou. Este curso e outros conhecimentos e técnicas aprendidos com a ONG é de grande ajuda na manutenção de sua propriedade. Como exemplo, Jf retrata um momento em que utilizou a homeopatia para salvar um de seus animais (uma vaca) que foi picada por uma cobra. Esta ligação com o CAPA é benéfica para esta produtora, pois a ONG repassa conhecimento aos produtores tornando-os mais independentes com relação a sua propriedade, pois, após obterem conhecimento eles têm liberdade de quando e como aplicar este saber em sua lavoura ou animais.

Além de Jf, Bm também utiliza alguns saberes e técnicas. $\mathrm{O}$ agricultor enumera a criação de galinhas, vacas e suínos em sua propriedade, bem como também a plantação de grãos. Essa diversificação na propriedade é importante, pois Bm ressalta que não se arrisca a viver apenas da agroindústria, que, segundo seus cálculos, não daria para sobreviver apenas da produção agroindustrial. Altieri (2004) concebe técnicas básicas para uma estratégia agroecológica como: controle de erosão, reciclagem de nutrientes, controle biológico natural, diversificação temporal e diversificação espacial, esta última implica em sistemas mistos de plantio e criação de animais, 
como tem feito Bm. Wezel et al argumenta que a agroecologia como prática faz uso de procedimentos como: fertilidade do solo, conservação de recursos naturais, gestão de matérias orgânicas e biodiversidade dos agroecossistemas, este último também praticado por $\mathbf{B m}$, alguns destes conhecimentos adquiridos através do contato com a assistência técnica.

Am relata uma das técnicas que o mesmo desenvolve em sua propriedade, que é a utilização de composto ${ }^{5}$ feito por ele mesmo e aplicado no cultivo de tomates. Este composto Am aprendeu com o suporte técnico. Por sua vez, Em também explica duas técnicas usadas na época em que praticava agroecologia, como adubação verde e técnicas para deter plantas invasoras. Ambas aprendidas com o técnico agrícola.

Entendemos que estes produtores souberam incorporar em suas práticas agrícolas as técnicas ensinadas pelo suporte. O conceito de Agência de Long (2002) esclarece a competência dos indivíduos de processarem suas experiências aprendendo com o conhecimento empírico de outros autores, como percebemos nos relatos de Jf que aprendeu homeopatia com os técnicos do CAPA, de Am que aprendeu a fazer um composto orgânico para usar em seus cultivos, e as técnicas aprendidas por Em como adubação verde e controle de plantas invasoras.

Estes conhecimentos ateóricos dos agricultores são provenientes de conexões externas à propriedade, neste caso mais específico a ONG CAPA e o técnico da BIOLABORE. Estas ligações são advindas das redes nas quais estes produtores estão inseridos; estas redes por sua vez propiciaram estes saberes $a$ teóricos aos produtores. Laraia salienta que as mudanças culturais provindas de fatores culturais externos são mais rápidas, como ficou notório nos novos hábitos produtivos adquiridos pelos agricultores.

Contudo, apesar dos diversos benefícios proporcionados pela assistência técnica, evidenciamos no estudo outro "lado" deste suporte oferecido aos agricultores. Esta outra faceta do suporte técnico oferecido pela ONG CAPA e pelo técnico da BIOLABORE implica, em nossa observação, em uma grande dependência dos produtores destes órgãos, como ficou evidente no caso da agricultora Jf. A agricultora Jf destaca que uma de suas dificuldades é a perda de produção, porém, a mesma também destaca que essa diminuição da produtividade também é consequência da ausência de assistência do técnico da BIOLABORE:

[...] então agora, recentemente, a gente teve é... não foi perda... estes tomates que está na feira ${ }^{6}$, se você olha, você vai vê, era pra produzi bem mais, mas a gente é uma... que o técnico ele ta meio que meio que afastado, porque teve um problema que não foi assinado umas papelada pra ele, daí ele não trabalho, daí a gente não tinha muito a onde busca né [...] (Jf: entrevista 1 Agricultora, pesquisa de campo, linha 184-188).

\footnotetext{
${ }^{5} \mathrm{O}$ agricultor Am não deixa claro o que é esse composto e como é feito.

${ }^{6}$ Quando Jf explicita "feira” esta se referindo a associação AAFEMED.
} 
Este fator também é destacado pelo agricultor Am que diz: "essa é uma grande dificuldade". Além de precisar do técnico para auxílio na produção, Am também precisa do técnico para planejar a venda de seus produtos, pois ele admite que não consegue realizar um bom planejamento sozinho. Neste sentido, podemos ressaltar a grande dependência que os produtores têm do técnico, tanto no setor produtivo como também no planejamento da venda da produção.

Essa dependência salientada por Jf e Am do técnico é ocasionada devido a falta de conhecimentos destes produtores tanto do setor produtivo como, no caso de Am, socioeconômico. Essa "dependência" dos produtores agroecológicos resulta, em nosso entendimento, em uma maior dificuldade na manutenção da agroecologia, pois se num dado momento os agricultores ficarem sem assistência técnica, os mesmos terão dificuldades em prosseguir com seus empreendimentos.

Nota-se que a assistência técnica influencia a agroecologia de duas maneiras, num primeiro momento ajuda os produtores praticá-la, contudo em face desta dependência técnica dos agricultores, prejudica-os caso esta assistência seja cancelada. Também foram identificados na pesquisa, alguns fatores externos que interagem com a agroecologia, debateremos a seguir.

\section{Fatores Externos e Agroecologia}

Alguns aspectos externos do meio rural também influenciam na agroecologia. Para Bm, por exemplo, um fator relevante na opção pela prática agroecológica foi a influência de um técnico agrícola ${ }^{7}$. Após a sugestão desse técnico de praticar uma agricultura mais ecológica, o agricultor afirma que deixou definitivamente de usar agrotóxicos. Porém não foi somente a sugestão do técnico agrícola que o influenciou. Ao ser questionado se tinha mais algum elemento que o levou à agroecologia, ele responde que os agrotóxicos não fazem bem, que na atualidade “tem muito veneno, o veneno tá tomando conta já das águas, do ar" (Pesquisa de Campo linhas 76-77). Nota-se que Bm expressa uma visão de mundo - no sentido de Mannheim - que se conecta com elementos do movimento ambiental global, ligando $\mathbf{B m}$ aos conteúdos difundidos pelas $\mathrm{ONGs}^{8}$. Em outro momento da entrevista $\mathbf{B m}$ ressalta a importância de produzir alimentos saudáveis, e nota-se, novamente, influência externa em sua opinião. Ele explica que aprendeu em cursos que não trabalha apenas para ele, mas também para os outros. Constatamos que esta opinião de Bm foi influenciada por agentes externos que promovem a agroecologia.

\footnotetext{
${ }^{7}$ Bm não deixa claro quem é este técnico.

${ }^{8}$ A ONG responsável pelos cursos sobre agroecologia na região Oeste do Paraná é o CAPA - Centro de Apoio ao Pequeno Produtor - núcleo Marechal Candido Rondon.
} 
Este fator externo também é encontrado nos outros agricultores. Na concepção de Jf, as ONGs propiciam bastante suporte aos agricultores agroecológicos, principalmente no requisito de conhecimentos adquiridos em cursos e palestras. Já para o agricultor Am, o início da prática agroecológica deu-se por intermédio de cursos realizados pelo CAPA. Foi com os cursos promovido por esta instituição que Am dá os primeiros passos para praticar agroecologia.

E, por último, Em afirma que após sofrer a contaminação por agrotóxicos, ficou sabendo que o sindicato do trabalhador promoveria um curso sobre agroecologia. Para Em, naquele momento, foi uma alternativa, pois o mesmo não podia mais mexer com agrotóxicos e esta prática agrícola dava-lhe uma opção; nas palavras de $\mathbf{E m}$ "eu tinha que saí fora do veneno, então pra mim foi um prato cheio" (Em Entrevista 1 agricultor, Pesquisa de Campo, Linhas 57-58).

A influência externa também é enfatizada por Bauer e Mesquita (2008). Estes autores destacam que as ONGs têm um importante papel no ingresso dos agricultores na agroecologia através de palestras e cursos, e, também, as ONGs são importantes na fase inicial da adoção da agroecologia.

Entendemos que estas conexões externas dos agricultores ajudaram os mesmos a adotarem a agroecologia. Estas redes propiciaram mutações nos hábitos dos agricultores; neste sentido, Laraia (2009) destaca que as mutações culturais podem ser externas ou internas. Neste caso, são mudanças externas, porque ocasionaram mudança nos hábitos produtivos destes produtores. Long (2002) com o conceito de "campos de batalha do conhecimento" enfatiza as mudanças sociais provenientes de projetos de desenvolvimento rural, neste caso, os projetos de agroecologia propiciaram mutações não apenas no aspecto produtivo, mas também no conhecimento dos produtores que trazem consigo visões de mundo que para se firmarem se contrapõem aos pacotes tecnológicos da agricultura, nesse processo ocorrem tensões com o mercado, com as técnicas adotadas pela agricultura convencional e também, muitas vezes, com os vizinhos que se utilizam de agrotóxicos que não raro contaminam a produção agroecológica. Podemos constatar as mutações nas falas de Bm e Jf. No mesmo sentido, Caporal (2011) destaca que a agroecologia propicia saberes de diversas áreas do conhecimento.

Outro aspecto externo que faz com que os produtores se mantenham na agroecologia é a associação de agricultores. Am é questionado se a associação de agricultores é importante para ele, o agricultor responde que ali foi o seu primeiro ponto de venda. A associação permite a Am comercializar seus produtos tendo uma margem de lucro superior a outros mercados.

Com Em também ocorre o mesmo, segundo ele, vender sua produção na associação, sem um atravessador, é uma forma de "driblar o mercado", porque dessa forma aumenta o lucro e lhe permite ter uma vida melhor. Buainain (2006) destaca que os produtores que possuem ligações com o mercado têm uma vida melhor do que os agricultores que não as possuem. 
A agricultora Jf também destaca que a associação é benéfica para sua família, "a associação para nós é fundamental, pois é o nosso mercado" (Jf: entrevista 1 Agricultora, pesquisa de campo, linha 222). Além de ser um ponto de venda, a associação também propiciou a assistência técnica, que antes da criação da associação eles não dispunham. A AAFEMED também é ligada à Cooperativa da Agricultura Familiar e Solidária do Oeste do Paraná COAFASO- que permite o convênio com o PAA e PNAE. Segundo Abramovay (2005), a formação de empreendedorismos coletivos provindos dos agricultores é verdadeiro exemplo de organização, que propicia aos produtores adentrarem no ambiente de comercialização.

O produtor Bm explica que pode vender seu produto na associação de Medianeira ou na feira-livre de Foz do Iguaçu. Bm dispõe de mais de uma opção de mercado para vender seus produtos, isso só é possível pois a AAFEMED possui convênio com a COAFASO, com isso os agricultores da associação AAFEMED podem vender seus produtos em outros pontos de venda, no caso de Bm, em Foz do Iguaçu. O contrário também pode ser feito, ou seja, produtores da cidade de Missal, Foz do Iguaçu ou outra cidade, desde que suas associações possuam convênio com a cooperativa COAFASO, podem vender seu produto na AAFEMED.

O conceito de rede da TAR significa que os recursos estão concentrados em poucos locais, mas a partir do momento que os atores conectam-se a estes locais para terem acesso a estes recursos, uma rede começa a ser formatada. Em nosso caso, este recurso destacado pela TAR é o aumento da renda familiar do produtor através da venda de seu produto, esta venda por sua vez é efetuada com a ajuda da associação, mais um ator da rede. A rede implica também em fatores culturais, pois como nos ensina Geertz, o homem é um animal preso a uma teia de significados formatada por ele mesmo, sendo a cultura esta teia e suas análises. Pelo conceito significado entendemos como algo importante, que tem sentido e valor para o indivíduo. Compreendemos que a associação é importante para os produtores, por dois motivos: primeiro pela importância dada à associação pelos produtores entrevistados, uma vez que é através dela que eles colocam seus produtos no mercado, e em segundo lugar sabemos que houve muita luta e esforço por parte dos agricultores para a criação da AAFEMED.

Outra influência externa constatada na pesquisa, são os programas do governo Federal; o Programa de Aquisição de Alimentos (PAA) e o Programa Nacional de Alimentação Escolar (PNAE). Estes programas são ações para fortalecer a agricultura familiar. Jf é questionada sobre o que ajuda os produtores agroecológicos e ela responde que o que um dos benefícios do PAA e PNAE, é que através dos programas, os agricultores têm a "produção garantida", em outras palavras, sua produção não ficará dependente de consumidores, que podem comprar ou não os produtos, pois já foi comprada pelos programas federais. Os agricultores Am e Bm também destacam a ajuda proporcionada pelos programas do Governo Federal, ambos lembram que 
recebem trinta por cento a mais pelos produtos e também esclarecem que esta porcentagem a mais paga pelos seus produtos não é paga pelos mercados "comuns".

Long enfatiza que os campos de batalha do conhecimento não se restringem somente ao local e podem fazer parte de projetos maiores, que tentam abarcar um grande número de atores sociais; um exemplo disso é o PNAE e o PAA. Estes dois programas governamentais proporcionam aos agricultores familiares agroecológicos um diferencial ao assegurar $30 \%$ a mais pela sua produção. Esta remuneração a mais resulta em benefícios aos produtores tendo por consequência mudanças sociais. As mudanças sociais estão implícitas nessa maior arrecadação, pois desta maneira os produtores podem renovar ou adquirir novos equipamentos para a propriedade, adquirir recursos para melhorar a produção, ou qualquer outro beneficio advindo do dinheiro.

Entendemos também que estes fatores externos acabam se "misturando" com hábitos culturais rurais, tendo por consequência uma cultura rural híbrida. Estes hibridismos do meio rural também influenciam a agroecologia como vemos a seguir.

\section{"Mundo" Rural Híbrido}

Durante a pesquisa, percebemos que não existe uma cultura rural "pura", mas sim, hibrida, ou seja, uma cultura constituída tanto de aspectos rurais como de fatores externos ao ambiente rural. Um exemplo de um aspecto externo ao ambiente rural evidenciado na pesquisa, é a atividade não agrícola praticada por $\mathbf{B m}$.

Bm possui em sua propriedade uma agroindústria na qual produz melado e açúcar mascavo. Ele planta cana de maneira orgânica, sem adição de produtos químicos, e usa essa matéria prima na fabricação de produtos agroecológicos.

Segundo Buainain et al (2003), na atualidade o emprego não-agrícola está permeando o mundo rural. Contudo o emprego não-agrícola de $\mathbf{B m}$, na sua agroindústria, é um fator que faz com que Bm permaneça na agroecologia. Na concepção de Bauman (2012), cultura possui uma faceta conservadora e outra mutável, uma se apresenta como ferramenta de perpetuidade e a outra como ferramenta da mudança. Podemos destacar que foi isso que aconteceu com o produtor $\mathbf{B m}$, ele manteve a prática agrícola em sua propriedade, mas incorporou o novo, abriu uma agroindústria. Isso gera o hibridismo da cultura rural, enfatizado por Eagleton como uma "mistura" de hábitos culturais distintos.

No entanto, identificamos também que alguns hábitos rurais são preservados pelos agricultores. O agricultor Bm, por exemplo, retrata que seu pai sempre o aconselhou manter um pouco de mata na propriedade, para que quando precisasse de lenha, teria disponível no local. Bm seguiu o conselho de seu pai, e, atualmente, retira lenha da própria mata para usar em sua 
agroindústria. A agroindústria por sua vez é mantida com a plantação de cana agroecológica. Estes saberes tradicionais recuperados e preservados através da agroecologia nos remetem ao conceito cultura e significados de Long (2002). Para Long os valores e hábitos culturais não são apenas culturalmente construídos, mais são aplicados de diferentes maneiras. Nota-se que o hábito de preservar um pedaço de mato para retirar lenha para consumo próprio foi passado para Bm que aplicou este hábito de uma nova forma, ou seja, Bm não usa a lenha retirada da mata apenas para o autoconsumo, mas também a usa em sua agroindústria.

Perguntamos a Am se algum hábito de seus antecessores era conservado por ele e Am responde que o hábito de plantar para o próprio consumo era praticado pelos avós, e ainda era mantido em sua propriedade. Outro costume herdado, o uso da enxada; essa ferramenta que foi "aposentada" por muitos agricultores que se "modernizaram" ainda é usada por Am no controle de plantas invasoras. Leff (2002) esclarece que as práticas agroecológicas facultam na recuperação de saberes e práticas tradicionais, como é o caso de Am que voltou a usar a enxada na propriedade.

O produtor Em retrata: "comecei a trabalha com meu pai desde os oito anos, e ali a gente aprendeu muita coisa" (Em Entrevista 1 agricultor, Pesquisa de Campo, Linha 07). Muitos conhecimentos e tradições foram preservados pelo agricultor, como o costume de plantar feijão e milho para o próprio consumo.

A utilização destes saberes tradicionais, neste caso o plantio para o próprio consumo, é encontrado em Caporal, Altieri e Gliessman; estes autores retratam a importância que os saberes e práticas populares têm para a agricultura agroecológica.

Vimos que os hábitos culturais são preservados pelos agricultores, como naquele hábito de plantar para o próprio consumo, e, simultaneamente, novos padrões culturais são incorporados pelos atores do meio rural, como, por exemplo, abrir uma agroindústria. A hibridização cultural é importante, em nossa percepção, porque faz com que os produtores pesquisados se mantenham na agroecologia.

Após a exposição de todos estes fatores que interagem de maneira significativa com a agroecologia, achamos importante também expor algumas percepções dos atores entrevistados sobre o "mundo agroecológico".

\section{Percepções Sobre o "Mundo Agroecológico"}

Perguntamos a Em se há fatores culturais que influenciam na agroecologia. Ele respondeu que as pessoas que não moram no meio rural e pretendem praticar agroecologia teriam que começar na escola. Entendemos que Em vê a educação como uma "ponte" entre a agroecologia e pessoas que não vivem no meio rural. Dessa forma reportamo-nos a Laraia 
(2009), que afirma que a cultura é dinâmica, novos saberes e habilidades podem ser adquiridos pelos indivíduos e esta aquisição é acumulativa. Com isso, novos saberes agroecológicos seriam aprendidos na escola.

O agricultor Em também critica os meios de comunicação por veicularem apenas propagandas que privilegiam o agronegócio, segundo ele, deveriam dar maior importância aos pequenos produtores e à agroecologia. É interessante a opinião de Em, que vai de encontro às ideias da Teoria Ator Rede (TAR). A TAR explica que estamos inseridos em redes, estas redes propiciam conexões com materiais humanos e não humanos. A formatação de uma rede mais "forte" que possua ligações com o mercado da propaganda, também iria "fertilizar" a adoção da agroecologia.

Estas duas opiniões de Em fazem parte de sua visão de mundo, e foram importantes para a análise da nossa pesquisa, uma vez que, se ambas as visões se concretizassem mais atores adotariam a agroecologia.

Outro fator importante que evidenciamos na pesquisa e que contribui para a manutenção da agroecologia é o gosto pelo meio rural e pela agricultura agroecológica. O agricultor $\mathbf{B m}$, por exemplo, destaca que estudou um pouco, e com a idade de quinze anos largou a escola para trabalhar no meio rural, segundo o agricultor, ele "gostava mais da roça". Bm aos setenta anos está muito bem de saúde. Bm também conta que muitas pessoas dizem para ele se aposentar, contudo, ele ressalta que gosta do que faz, que se sente bem com o seu trabalho na propriedade.

Este fato também é enfatizado por Jf. Ela retrata que seu filho mais velho pretende ingressar numa universidade e após o término da graduação quer voltar para a propriedade. Segundo Jf, um dos motivos de seu filho ter esse pensamento é o gosto pela prática agrícola.

A própria Jf gosta de praticar a agroecologia, sente-se bem e diz: "nós vivemos no paraíso e nem se damo conta né” (Jf: entrevista 1 Agricultora, pesquisa de campo, linha 102). Outro ponto que deixa claro o gosto de Jf pela agroecologia é quando lhe perguntamos se pretende continuar na agroecologia. A produtora responde que sim e se possível aumentar a prática.

Segundo Eagleton (2005) cultura é em grande medida aquilo para o que vivemos: afeto, relacionamento, satisfação emocional, lugar, comunidade, um sentido de significado último. Neste sentido, entendemos que o gosto de $\mathbf{B m}$ e do filho de $\mathbf{J f}$ pelo meio rural implica em uma satisfação emocional, algo que dá um sentido para estes agricultores, este aspecto faz com que Bm e filho de Jf permaneçam no meio rural e, consequentemente, continuem na agroecologia. Nesta mesma ideia esta a satisfação de Jf em praticar agroecologia. Entendemos que a agroecologia propiciou para esta agricultora um prazer intelectual, uma satisfação emocional. 
Esta preferência pela agroecologia e pelo ambiente rural faz com que a agroecologia seja perpetuada.

Em alguns momentos, os atores pesquisados explicitaram suas opiniões sobre o futuro da agroecologia. O produtor Am acredita em um futuro melhor para os agricultores agroecológicos devido principalmente ao uso de agrotóxicos na agricultura convencional o que implica em uma maior procura por parte dos consumidores de alimentos saudáveis, ou seja, agroecológicos.

O produtor Em também expressa sua concepção sobre o futuro da agroecologia, para ele, a agroecologia vai crescer, pois os consumidores estão mais informados sobre o mal causado pelo uso dos agrotóxicos, enquanto os produtos "naturais" são "puros", não prejudicam a saúde. Jf também é questionada sobre o futuro da agroecologia e ela responde:

Se a gente consegui mais outras pessoas que aderirem ao mesmo procedimento de produção ${ }^{9}$ eu acredito que vai ser um futuro esplendor agora se fica só nos pingado até quando que estes poucos vão conseguir segura porque é uma questão às vezes de a gente consegui mais por que pra aumenta a produção e mostra mais por que a gente não é muito visto né, a prática orgânica não é muito vista uma porque a produção é pouca né, não aparece, pouco aparece né ,então eu acredito que tem que te ela vai ter futuro se mais pessoas aderirem a causa né, e quem sabe alguns intoxicados que nem nós né (Jf: entrevista 1 Agricultora, pesquisa de campo, linhas386-394).

Segundo Jff, ainda há poucos produtores que adotaram o sistema de produção agroecológico, e esta modalidade de cultivo só terá futuro com a adesão de mais agricultores. Para ela, um fato que pode fazer com que mais pessoas mudem para o sistema agroecológico é a intoxicação por veneno, que é recorrente entre os agricultores do sistema convencional.

Mannheim (1952) nos ensina que as visões de mundo são constituídas das vivências e experiências dos indivíduos, ou seja, as visões de mundo são formatadas a partir de saberes ateóricos. Contudo, as visões de mundo também podem ser constituídas de conhecimentos teóricos, neste sentido estão implícitas as ideologias do indivíduo. Mannheim também adverte que as visões de mundo não são descabidas de sentido, e fazem parte do produto cultural. Entendemos que as três visões de mundo dos atores, destacadas anteriormente, fazem parte da totalidade cultural. Ambos os agricultores enfatizam que o futuro da agroecologia pauta-se pela qualidade dos produtos, e, especificamente, Jf ressalta que mais agricultores devem aderir a agroecologia para a mesma "ter um futuro esplendor". Entendemos que estas visões de mundo destacadas são importantes para a manutenção da agroecologia.

\section{Considerações Finais}

\footnotetext{
${ }^{9}$ Este método que $\mathbf{J f}$ se refere é a agroecologia.
} 
Nas falas dos agricultores observamos que a adoção ou não da agroecologia pode ser influenciada de diversas maneiras por distintos aspectos que se encontram nas estruturas da sociedade naquilo que comumente chamamos de cultura. $\mathrm{O}$ sentido da cultura aqui enfatizado não é o de uma definição de uma corrente antropológica específica, o que procuramos enfatizar neste artigo é o conceito de cultura no sentido dado pelos próprios agricultores agroecológicos, analisando como eles constroem sua narrativa pois, como nos ensina Mannheim, as visões de mundo dos atores sociais fazem parte da totalidade cultural e a eles cabe sua própria interpretação e leitura. E, a partir dessas leituras, que busca compreender com agem e interpretam suas ações no mundo, os atores navegam por uma enorme variedade de conceitos que os conectam a diversas redes de produção e consumo e essas redes, por sua vez, os ligam à forma como produzem e reproduzem suas vidas. E é importante que a ciência observe que eles o fazem como uma reflexão que conta e reconta sua história, sua cultura e seus valores e não como uma mera reação a algo exterior cuja origem se dá apenas na esfera econômica. Dessa forma podemos observar nas falas a existência de outras camadas de valor que extrapolam a racionalidade instrumental do Homo Economicus.

Os sujeitos evidenciaram que sua cultura e suas interpretações do mundo interagem de forma intensa com a agroecologia, influenciando produtores agroecológicos a aderirem e a permanecerem nesta prática, bem como, também a de não a adotarem ou de não se manterem na mesma. A compreensão dessas variáveis pode constituir um rico instrumento de análise de formas de abordagem, compreensão de valores, limites e possibilidades de modos mais ecológicos de produção. À guisa de conclusão observamos que os estudos nesta perspectiva analítica devem ser realizados, para trazerem à tona outras evidências dos complexos processos que envolvem a adoção de práticas ecológicas por um grupo de agricultores e contribuir para melhorar a agroecologia como alternativa produtiva.

\section{Referências}

ALTIERI, M. Agroecologia: A dinâmica produtiva da agricultura sustentável. Porto Alegre. $4^{\circ}$.ed. Editora UFRGS. 2004.

ABRAMOVAY, R. De Camponeses a Agricultores: Paradigmas do Capitalismo Agrário em Questão. 1990. 376 p. Tese. UNICAMP. Campinas.

ABRAMOVAY, R, et al. Agricultura Familiar entre o Setor e o Território. São Paulo. 2005. Disponível $\mathrm{em}:<$ http://www.oikonomika.com.br/artigos/A_agricultura_familiar_entre_o_setor_e_o_territorio.pdf $>$ Acesso em: 12 de jan.2015.

BOHNSACK, Ralf. Documentary Method. In: FLICK, Uwe. The SAGE Handbook of Qualitative Data Analysis. Los Angeles; Londres; Nova Deli; Singapura; Washington DC: SAGE, 2014. P. 217-233. 
BRANDENBURG, A. Movimento agroecológico: trajetória, condições e perspectivas. Curitiba. 2002.

http://www.anppas.org.br/encontro_anual/encontro1/gt/agricultura_meio_ambiente/Alfio\%20

Brandenburg.pdf $>$ Acesso em: 06 de jan.2015.

BUAINAIN, A. M. et al. Agricultura Familiar e o Novo Mundo Rural. Porto Alegre. 2003. Disponível em: $<$ http://www.scielo.br/pdf/soc/n10/18723.pdf $>$ Acesso em: 10 de jan. 2015.

BAUMAN, Z. Ensaios Sobre o Conceito de Cultura. Rio de Janeiro, Zahar. 2012.

BUAINAIN, A. M. Agricultura Familiar, Agroecologia e Desenvolvimento Sustentável: Questões para Debate. Brasília. IICA: 2006.

CALLON, M. Some elements of a sociology of translation: domestication of the scallops and the fishermen of St Brieuc Bay First.In. J. Law, Power, action and belief: a new sociology of knowledge? London, Routledge.1986. Disponível em:<http://www.vub.ac.be /SOCO/tesa/RENCOM/Callon\%20 (1986)\%20Some\%20 elements $\% 20$ of $\% 20 \mathrm{a} \% 20$ sociology $\% 20$ of $\% 20$ translation.pdf.

CALLON, M. A agonia de um laboratório. 1995. Disponível em: <http://www.necso.ufrj.br/Trads/> Acesso em: 02 de maio. 2015.

CALLON, M. Rede de concepção e adoção tecnológica: lições para o praticante da ACT. 1995. Disponível em: <http://www.necso.ufrj.br/Trads/> Acesso em: 03 de maio. 2015.

CAPORAL, F.R; COSTABEBER, J. A. Agroecologia: alguns conceitos e princípios. Brasília. 2004. Disponível em:< http://www.agroeco.org/socla/archivospdf/AgroecologiaConceitos\%20e\%20princpios1. pdf > Acesso em: 02 de jan. 2015.

CAPORAL, F. R. Agroecologia: uma nova ciência para apoiar a transição a agriculturas mais sustentáveis. In. Princípios e Perspectivas da agroecologia. Paraná. Instituto Federal do Paraná. 2011, p.83-119.

EAGLETON, Terry. A Idéia de Cultura. São Paulo: Editora Unesp. 2005.

GLIESSMAN, S.R. Agroecologia: Processos Ecológicos em Agricultura Sustentável. Porto Alegre. $1^{\circ}$ ed. Editora UFRGS. 2000.

LARAIA. Roque B. Cultura um Conceito Antropológico. 24 . ed. Rio de Janeiro: Zahar. 2009. LONG, N. An Actor-oriented Approach to Development Intervention. In: Rural Life Improvement in Asia: Report of the APO Seminar on Rural Life Improvement for Community Development. 2002.

LATOUR, B. Ciência em Ação: como seguir cientistas e engenheiros sociedade afora. São Paulo. Editora Unesp. 2000.

LATOUR, B. Jamais Fomos Modernos. Ensaio de Antropologia Simétrica. $1^{\text {a }}$ ed. Rio de Janeiro: Editora 34. 1994.

LEFF, E. Agroecologia e Saber Ambiental. Porto Alegre. 2002. Disponível em: $\langle$ http://www.pvnocampo.com.br/agroecologia/agroecologia_e_saber_ambiental.pdf $>$ Acesso em: 01 de maio. 2015.

MANNHEIM, Karl. Beiträge zur Theorie der Weltanschaungsinterpretation. In: Wissenssoziologie. [orig.: 1921/22]. Neuwied: Luchterhand, 1964. p. 91-154.

MANNHEIM, K. On the interpretation of Weltanschauung. In ibid. Essays on the sociology of Knowledge. London: Routledge \& Kegan Paul p. 33-83.1952.

WELLER, Wivian et al . Karl Mannheim e o método documentário de interpretação: uma forma de análise das visões de mundo. Soc. estado., Brasília, v. 17, n. 2, p. 375-396, Dec. 2002. Available from $\quad<$ http://www.scielo.br/scielo.php?script=sci_arttext\&pid=S0102- 
$69922002000200008 \& \operatorname{lng}=$ en $\& n r m=$ iso $>$.

Acesso

em

10 maio 2016.

http://dx.doi.org/10.1590/S0102-69922002000200008.

WEZEL, et al. Agroecology as a science, a movement and a practice. A review. 2009. Disponível em:<http://agroeco.org/socla/wp-content/uploads/2013/12/wezel-agroecology.pdf> Acesso em: 01 de abr.2015. 